\title{
An Ecological Research on Bachelor's Degree Thesis of English Major Students
}

\author{
Qiong Fang \\ School of Foreign Languages, Anhui Sanlian University, Hefei 230601, China
}

\begin{abstract}
This paper takes an ecological approach to looking at the teaching of undergraduate English majors, an approach that regards the whole process of teaching as a series of transmission and transformation of energy. The research indicates that the writing of bachelor's degree thesis is at the final stage of undergraduate study and is therefore on the basis of previous curriculum, from which it extracts energy. Consequently, it concludes that the accomplishment of bachelor's degree thesis of English majors depends on the whole process of undergraduate study, not just the thesis writing itself, and suggests to reform the curriculum, including re-evaluate "specialized knowledge" courses, strengthen the teaching of writing, and pay more attention to the cultivation of critical thinking and innovation of the students.
\end{abstract}

Keywords: English major; bachelor's degree thesis; ecosystem of teaching; trophic level; energy transmission.

\section{Introduction}

Being a major course of undergraduate English majors, the writing of graduation thesis reflects the students' language competence as well as their knowledge and ability. Problems existed in topic selection, thesis outline, language, etc. of the thesis have attracted the attention of all the parties concerned. This paper makes a study into factors influencing the final writing of the thesis from the perspective of ecology of education. On the basis of overall process of undergraduate teaching, this paper tries to find out approaches to improve the quality of graduation thesis and comprehensive ability of English major students.

\section{Analysis of the Teaching Ecosystem of English Majors}

By ecosystem, it means an entity at a certain time and space in which biotic communities and their abiotic environment interact and influence each other through energy flow and material cycle. This system is self-regulated. All the factors involved in the teaching of English majors comprise an ecosystem, including students, teachers, curriculum, natural environment, social environment, among other things. Similar to other ecosystems, this system has the features of energy flow, material cycle and message transfer. Research in this paper is from the perspective of energy flow. In an ecosystem, energy flows from the bottom to the top unidirectionally, from a lower trophic level to a higher one [1]. In an ecosystem of English teaching, external energy enters into the system in the forms of capital, matters or information, etc. Along with the whole process of undergraduate teaching, external energy is digested and assimilated, flowing from the bottom trophic level to the top one.

Trophic level is a classification of biotype proposed by American ecologist Raymond Laurel Lindeman (1942). According to him, in a natural ecosystem, some organisms provide others with energy. The relations between providers and receivers form a complex food chain, in which, organisms at the lower level provide the organisms at the higher level with nutrient. There is a certain location for each type of organism in a food chain, and this location is called trophic level. Different organisms are located at different trophic levels. External energy flows into the first trophic level, where it moves along the food chain towards the top [2]. In this process, organisms at higher trophic levels get energy from organisms at lower levels. In the past decades, along with the popularity of ecology of education, the concept of trophic level has also been used in the study of artificial ecosystem, including teaching ecosystem. In this paper, the constitution of teaching ecosystem of English majors will be studied on the basis of trophic level. 
Depending on the objective of research, trophic levels in an ecosystem can be classified in different ways. Classification in this paper is made in line with English Teaching Syllabus for English Majors (2000), which pointed out that foreign language talents in the $21^{\text {st }}$ century should be equipped with five characteristics, namely, "language competence, common-sense knowledge, professional knowledge, ability and quality" [3]. Based on these requirements, this paper divides the undergraduate teaching ecosystem of English majors into three trophic levels as shown in figure 1 by means of system analysis method of ecology [4]. Arrows in this figure indicate the direction of energy flow.

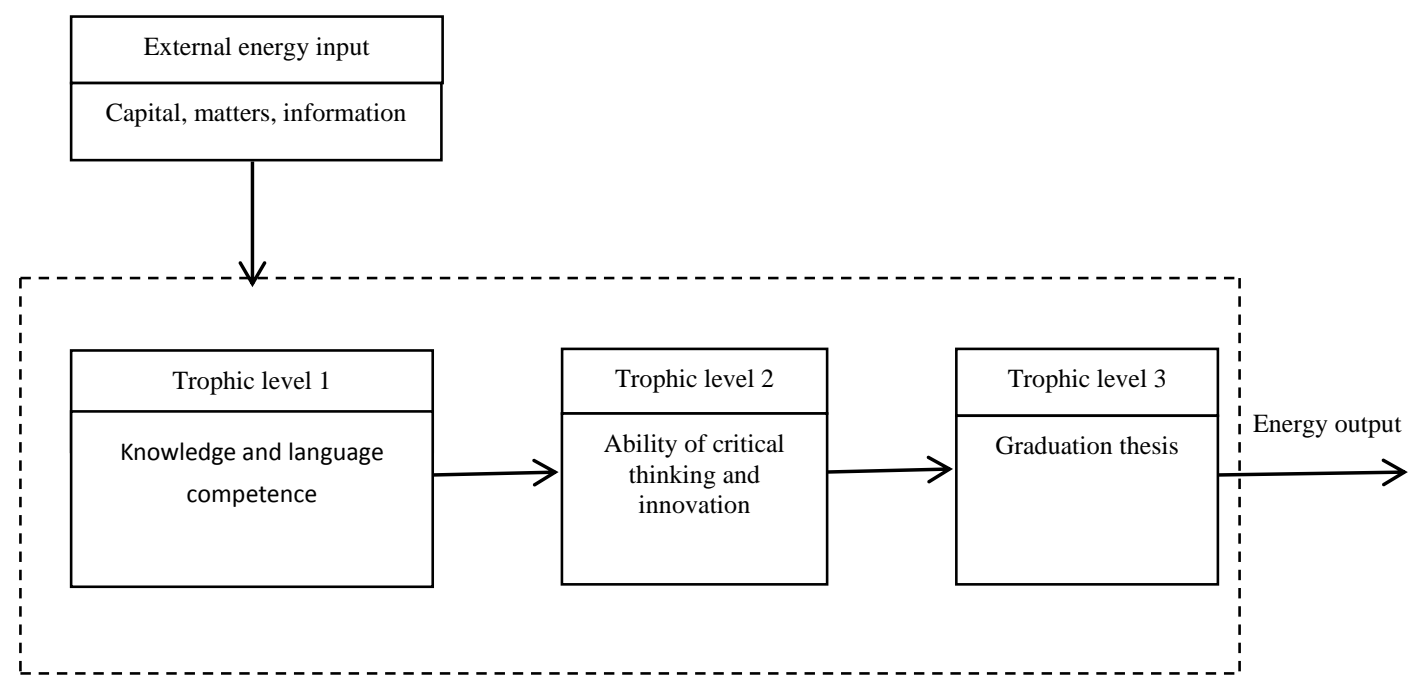

Fig. 1 Teaching ecosystem of English majors

As shown in figure 1, the three trophic levels play different roles in the system. Trophic level 1 consists of knowledge of language, culture, related profession, and language skills-listening, speaking, reading, writing and translating. This trophic level is the foundation of the whole system, which provides the latter trophic levels with energy. Having these knowledge and skills is a prerequisite for the students to write graduation theses well. From data collection, reading comprehension, selecting a topic to writing, knowledge and skills learned at trophic level 1 will always play a critical role. In addition, these knowledge and skills are also the basis for students' further study and their job in the future. All the other capabilities and qualities are developed on this basis. Therefore, in the process of acquiring knowledge and skills, students accumulate energy and get ready for study at latter trophic levels.

Trophic level 2 contains the ability of critical thinking and innovation. With only knowledge and skills students acquired at the first trophic level, it is unlikely for them to write a satisfactory graduation thesis. They have to be equipped with capability and quality, in particular, the capability of critical thinking. In modern society, the capabilities of thinking independently, analyzing and solving problems, expressing their opinions and communication are critical for college students of different majors, including English major students. In the meantime, innovation is another important factor that is used to evaluate the quality of a thesis. Innovation plays an essential role throughout the process of thesis writing, from selecting a topic to researching, making an outline, and writing. Innovation is also an important factor for students' career in the future.

Graduation thesis ranks the third trophic level. Being the last step of undergraduate teaching, the writing of graduation thesis should be carried out on the basis of the previous trophic levels, that is, knowledge and skills at trophic level 1 and capabilities at trophic level 2. Supposing that students have gained sufficient knowledge and skills, and have relevant capabilities from the previous stages of study, then energy input for thesis writing will be insured, and this will lead to a better thesis. On the contrary, if the previous courses failed to provide the students with appropriate knowledge, skills or capabilities, thesis writing will become more challenging for the students. 


\section{Problems and Their Causes}

A research conducted by the American ecologist Raymond Laurel Lindeman (1942) found out that in an ecosystem, energy diminishes level after level while flowing from the lowest trophic level to the highest one unidirectionally. According to Lindeman, a trophic level needs to consume energy to maintain its own function. Meanwhile, it is also required to transmit sufficient energy to the next trophic level. Usually, a trophic level can only transmit about $10 \%$ energy it possesses to the next level because the majority of energy is either consumed by itself or lost during the transmission. This is called Lindeman's law [10]. His study showed that in a typical ecosystem, energy owned by different trophic levels constitutes a pyramid, in which the lowest level has the largest proportion and the top level the least. This is called "ecological pyramid" or "pyramid of energy". Based on this model, energy in the teaching ecosystem of English majors should be arranged like a pyramid as shown in figure 2.

Such an ecosystem of English teaching performs well with sufficient energy, in which a trophic level is able to fulfil its own function and transmit adequate energy to the next trophic level at the same time. On this occasion, students will be equipped with a wide range of knowledge; their language competence will be ensured; they will have appropriate capabilities and as a result, there will be enough energy input into their graduation thesis. However, there are lots of problems existed in this ecosystem in reality and the actual structure of the teaching ecosystem often deviates from ecological pyramid. There are usually the following problems.

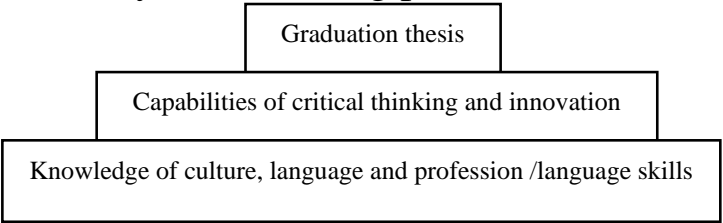

Fig. 2 An ideal teaching ecosystem of English teaching

\subsection{Uneven distribution of energy at trophic level 1}

Currently, much attention is paid to knowledge and language skills at this trophic level. Compare with other two trophic levels, this level get relatively more energy input. However, in many universities or colleges, the distribution of energy is uneven. Take writing as an example. Even though it is the most difficult language skill, it has not attracted enough attention. Such problems as insufficient class hours, little writing practice are very common in writing classes. To make the matter worse, curriculum is often influenced by tests and job market. For the courses that are not directly related to tests or job hunting, their class hours tend to be reduced. In the English Teaching Syllabus for English Majors (2000), there is a course entitled academic paper writing. A survey conducted by Sun Wenkang (2004) shows that many university and college in China have not had this course. Among the English majors being questioned, only 16.3\% students' respondents have this course for one semester. Up to $49.6 \%$ English majors have never had this course [6]. Similarly, courses on Western culture are often ignored. Owing to the problems with curriculum, students' knowledge acquired from English class is mostly limited to language. They learn very little about Western countries. As a result, it becomes very difficult for them to write graduation theses.

As for another aspect of trophic level 1, courses on related professional knowledge, while there are courses like finance English, international trade, legal English, and so on at different universities and colleges, more often than not, these courses are not so helpful for English major students as these courses usually use English version textbooks and English is used as the working language in class. Currently, however, in most universities and colleges in China, the number of English teachers with the expertise in related profession is obviously smaller than demand. In some cases, these courses are even taught by English teachers who know very little about the related subject. At the end of the course, some students are unable to read the passages, what they learn from these courses are just terminologies. In summary, being the foundation of teaching ecosystem of English majors, there are problems with the courses of knowledge and language skills, including the uneven distribution of class hours, unqualified teachers and so on. As a result, this trophic level is unable to provide the next trophic levels with sufficient energy. 


\subsection{Neglect of Trophic Level 2}

There are serious problems with the second trophic level-capabilities of critical thinking and innovation. Sun Youzhong (2011) pointed out that currently in China teaching for English majors just focus on knowledge and language, while other qualities and abilities of the students are neglected, in particular capabilities of critical thinking and innovation [7]. At macro level, much attention has been paid to the capability and quality of English majors. As early as 2000, English Teaching Syllabus for English Majors suggested to "strengthen the cultivation of capabilities of thinking and innovation of the students". Nevertheless, in many universities and colleges the focus of teaching for English majors is only knowledge and language skills. Compared with the ideal model shown in figure 2, only two trophic levels - "knowledge and skills" and "graduation thesis" are involved in their curriculum, while the second trophic level- "critical thinking and innovation" is almost neglected.

Anderson and Krathwohl (2001) made a classification of factors which have impact on the development of critical thinking capability and set up a model consisting of memory, understanding, application, analysis, comment and creation. According to this model, the impact of these six capabilities on the development of critical thinking capability increase in sequence. [8] If we take a look at the knowledge and language skill oriented teaching for English majors, we find that it puts much emphasis on the lowest levels - memory and understanding, while little attention is paid to those which have crucial influence on critical thinking capability-application, analysis and comment. As for the factor on top of the model, the most important factor of critical thinking capability - creation, it has rarely been involved in the curriculum. The long-term negligence of critical thinking and innovation capabilities has resulted in many problems. A well-known English-teaching scholar Huang Yuanshen (1998) commented that "for English majors, when they need to argue in a debate, discuss in a writing or ask a question in a lecture, they are often at a loss with nothing to say". He used a phrase "the absence of critical thinking" to describe this phenomenon. [9] So far, the problem of lack of critical thinking capability has not been solved. A survey conducted by Wen Qiufang et al. (2010) indicated that in the first three years of undergraduate study, the development of critical thinking capability of English majors is slower than student from other majors of liberal arts. She held that the impact of curriculum on critical thinking capability of English majors is not so active compared with that of other majors of liberal arts.[10]

\subsection{Insufficient Energy Input into Trophic Level 3}

Problems existed in the previous trophic levels lead to the poor quality of graduate thesis. During the supervision of graduation thesis writing, the author found out deficiencies of the students in both language and thinking. At language level, many theses have a small vocabulary, with lots of grammar mistakes and too many simple sentences. These theses are hard to read. Furthermore, lack of critical thinking and innovation is also very common. Take the selection of topic as an example. There is a lack of innovation for the majority of topics students selected. Many theses don't have a clear argument. Their theses are filled with literature review, background introduction, explanation of terminology and examples. Few students are able to put forward an argument and demonstrate it persuasively.

\section{Solution}

As the final step in the teaching ecosystem of English majors, the writing of graduation thesis needs to get energy from the previous teaching process, including knowledge and language teaching at trophic level 1 and development of capabilities of critical thinking and innovation at trophic level 2. Graduation thesis is a comprehensive reflection of undergraduate teaching process, and its quality is decided by the whole undergraduate teaching, not just the writing process. Therefore, to heighten the quality of graduation thesis, it is necessary to improve the complete teaching ecosystem, optimize the curriculum, and reform the contents and methodology of teaching. For the purposes of broadening students' horizon, develop their language competence and comprehensive quality, the author suggests to reform as follows. 
First, reform the curriculum of English majors. Selection of courses and class hours should be based on the sustainable development of the students, instead of catering to a specific examination or job hunting. In the meantime, the class hours of writing course needs to be increased to provide the students with more writing practice. It is also advisable to offer a course of academic paper writing. As for the "related professional courses" like international trade, legal English, etc., considering the lack of qualified teachers in many universities and colleges at the present, and therefore their ineffective results, it is suggested that different universities decide whether to keep them or not on the basis of their own condition.

Second, attention should be paid to the development of capabilities of critical thinking and innovation. To change the present situation of "the absence of critical thinking", we need to integrate the development of capabilities of critical thinking and innovation into the whole curriculum of English majors. We also need to pay attention to critical thinking and innovation in all the other relevant steps, including textbook writing, teacher development, teaching methodology, test, to name a few. The comprehensive optimization of the teaching ecosystem will provide graduation thesis writing with sufficient energy.

\section{Conclusion}

In summary, locating in the final trophic level of the teaching ecosystem, graduation thesis reflects the comprehensive effects of undergraduate curriculum of English majors. Lots of problems appearing in the thesis can be traced back to the previous teaching. Therefore, in order to improve the quality of graduation thesis to the greatest extent, attention should be paid to the whole process of undergraduate teaching. The long-term sustainable development of the students should be taken as the first priority to decide the curriculum, so as to optimize their knowledge structure, develop their language competence, capabilities of critical thinking and innovation and finally, the writing of their graduation thesis will become better, and their comprehensive quality will be greatly improved.

\section{Acknowledgments}

This research is financially supported by the Key Research Program of Humanities and Social Science of Anhui Education Department (SK2016A0341), Quality Engineering Program of Anhui Higher Education (2015tszy035), and Quality Engineering Program of Anhui Sanlian University (13zlgc051).

\section{References}

[1] Wu Dingfu, Wenwei Zhu. Education Ecology. Jiangsu Education Publishing House,1998, p86-88; P96-100

[2] Lindeman, R L. The Trophic-Dynamic Aspect of Ecology [J]. Ecology, 1942(10), p399-417

[3] The English Group of Foreign Language Teaching Committee of Higher Education. English Teaching Syllabus for English Majors. Foreign Language Teaching and Research Press, 2000.

[4] Zhou Xingdong, Li Shumin. Ecology research methods and applications. Heilongjiang people's publishing house, 2009.

[5] Smithson, P, Addison, K \& K Atkinson. Fundamentals of the Physical Environment. Third edition. London: Routledge, 2002.

[6] Sun Wenkang. An Analysis of the Present Situation of Bachelor's Degree Thesis Writing of English Majors. Foreign Language World, 2004(3), p50-64. 
[7] Sun Youzhong. Attaching Importance to the Development of Critical thinking Capability, Strengthening the Teaching Reform of English Major. Foreign Languages in China, 2011(5), p49-58.

[8] Ren Wen. Absence or Presence? Another Commentary on Critical Thinking Capability of Foreign Language Majors. Foreign Languages in China, 2013(1), p10-17.

[9] Huang Yuanshen. Absence of Critical Thinking. Foreign Languages and Their Teaching, 1998(7), p1; 19.

[10]Wen Qiufang, Wang Haimei, Wang Jianqing, et al. Comparative Study of Critical Thinking Capability English Majors and Other Liberal Arts Majors in China. Foreign Languages and Their Teaching, 2010(9), p350-355. 